University of Nebraska - Lincoln

DigitalCommons@University of Nebraska - Lincoln

$7-1-2001$

\title{
High-temperature magnetic properties of mechanically alloyed SmCo 5 and YCo5 magnets
}

\author{
I.A. Al-Omari \\ University of Nebraska - Lincoln \\ Ralph Skomski \\ University of Nebraska-Lincoln, rskomski2@unl.edu \\ R.A. Thomas \\ University of Nebraska - Lincoln \\ D. Leslie-Pelecky \\ University of Nebraska-Lincoln, diandra2@unl.edu \\ David J. Sellmyer \\ University of Nebraska-Lincoln, dsellmyer@unl.edu
}

Follow this and additional works at: https://digitalcommons.unl.edu/physicssellmyer

Part of the Physics Commons

Al-Omari, I.A.; Skomski, Ralph; Thomas, R.A.; Leslie-Pelecky, D.; and Sellmyer, David J., "High-temperature magnetic properties of mechanically alloyed SmCo 5 and YCo5 magnets" (2001). David Sellmyer Publications. 52.

https://digitalcommons.unl.edu/physicssellmyer/52

This Article is brought to you for free and open access by the Research Papers in Physics and Astronomy at DigitalCommons@University of Nebraska - Lincoln. It has been accepted for inclusion in David Sellmyer Publications by an authorized administrator of DigitalCommons@University of Nebraska - Lincoln. 


\title{
High-Temperature Magnetic Properties of Mechanically Alloyed $\mathrm{SmCo}_{5}$ and $\mathrm{YCo}_{5}$ Magnets
}

\author{
I. A. Al-Omari, R. Skomski, R. A. Thomas, D. Leslie-Pelecky, and D. J. Sellmyer
}

\begin{abstract}
The high-temperature coercivity of mechanically alloyed and subsequently annealed $\mathrm{RCo}_{5}(\mathrm{R}=\mathrm{Sm}$ and $\mathrm{Y})$ is studied. The annealed materials have the hexagonal $\mathrm{CaCu}_{5}$ structure with 2:17 (or 1:7) regions as a minor phase. High-temperature magnetic measurements show that the coercivities of materials decrease with increasing temperature from room-temperature to $873 \mathrm{~K}$, but that the temperature coefficient of the coercivity of $\mathrm{YCo}_{5}$ is much smaller than that of $\mathrm{SmCo}_{5}$. This behavior is explained in terms of the intrinsic temperature variation of the magnetocrystalline anisotropy.
\end{abstract}

Index Terms-Anisotropy, coercivity, finite-temperature magnetism, permanent magnets.

\section{INTRODUCTION}

$\mathbf{R}$ ECENTLY, samarium-cobalt based permanent magnets [1], [2] have attracted renewed interest due to their superior high-temperature properties [3]-[5]. In rare-earth transition-metal intermetallics, such as $\mathrm{SmCo}_{5}$ and $\mathrm{Nd}_{2} \mathrm{Fe}_{14}$, the rare-earth anisotropy is responsible for the high anisotropy (and coercivity), whereas the transition-metal sublattice produces a high saturation magnetization and Curie temperature [2], [6]. In almost all cases of interest, the magnitudes of the cobalt moments are somewhat lower than isotructural iron moments, but the strong interatomic exchange ensures a high Curie temperature and helps to realize a strong rare-earth anisotropy at and above room temperature. Typical $\mathrm{Sm}-\mathrm{Co}$ based permanent magnets are produced by sintering and are used as bonded magnets (single-phase $\mathrm{SmCo}_{5}$ based) or as $\mathrm{Sm}_{2} \mathrm{Co}_{17} / \mathrm{SmCo}_{5}$-based two-phase magnets [1], [2], although appreciable room-temperature coercivities of $17 \mathrm{kOe}[1.7 \mathrm{~T}]$ can also be obtained by mechanical alloying [7].

The pronounced temperature dependence of the rare-earth anisotropy makes the rare-earth sublattice comparatively unimportant at high temperatures [6], [8]. This effect is particularly important in rare-earth cobalt magnets with the hexagonal $\mathrm{CaCu}_{5}$ structure, where the $\mathrm{Co}$ atoms yield an unusually strong transition-metal contribution to the anisotropy. In fact, the first $1: 5$ permanent magnets in the late 1960s were $\mathrm{YCo}_{5}$ magnets, and only in the early 1970 s, when people began to recognize

Manuscript received October 12, 2000.

This work was supported by ARO/DARPA and CMRA

A. Al-Omari is with the Department of Physics and Astronomy and the Center for Materials Research and Analysis, University of Nebraska, Lincoln, NE 68588. He is on leave from the Department of Applied Physical Sciences, Jordan University of Science and Technology, Irbid-Jordan.

R. Skomski, R. A. Thomas, D. Leslie-Pelecky, and D. J. Sellmyer are with the Department of Physics and Astronomy and the Center for Materials Research and Analysis, University of Nebraska, Lincoln, NE 68588.

Publisher Item Identifier S 0018-9464(01)06878-9. the role of the rare-earth anisotropy, did emphasis shift toward samarium-cobalt magnets.

The practical idea behind the present work is to explore the feasibility of rare-earth free and therefore comparatively cheap high-temperature permanent magnets with moderate energy products (1 to $10 \mathrm{MGOe}$ ).

\section{SAMPLE PREPARATION AND STRUCTURE}

$\mathrm{SmCo}_{5}$ and $\mathrm{YCo}_{5}$ alloys were prepared by mechanical alloying from elemental powders. The starting Sm and Y powders are -40 mesh and $99.9 \%$ purity, while the Co powder is -325 mesh with a puritiesy of $99.8 \%$. The powders were alloyed and handled in an argon-filled glove box to prevent oxidation. The milling was performed in a hermetically sealed tungsten-carbide-lined vial in a SPEX 800 mixer/mill inside the argon-filled glove box, using a $3: 1$ ball-to-powder mass ratio. The milling was interrupted every two hours to remove a small amount of powder for x-ray diffraction and to break up clumps of powder. The x-ray diffraction patterns of the milled and unmilled powders are very similar to those shown in [7]. After milling for 16 hours, the $\mathrm{SmCo}_{5}$ material has an amorphous structure, but annealing at $800{ }^{\circ} \mathrm{C}$ for 5 min yields sharp diffraction peaks corresponding to $\mathrm{SmCo}_{5}$ with $2: 17$ (or $1: 7$ ) regions as a minor phase. The $\mathrm{YCo}_{5}$ samples, milled for 18 hours and annealed at $900{ }^{\circ} \mathrm{C}$ for $5 \mathrm{~min}$, exhibit a similar behavior.

\section{MAGNETIC PROPERTIES}

The samples were prepared by mixing the powder with Omega high-temperature cement and magnetizing in a field of $18 \mathrm{kOe}$. Hysteresis loops were measured by a vibrating sample magnetometer (VSM) in fields up to $10 \mathrm{kOe}$ and at temperatures from $20^{\circ} \mathrm{C}$ to $630^{\circ} \mathrm{C}$.

Fig. 1 shows the coercivities of $\mathrm{SmCo}_{5}$ and $\mathrm{YCo}_{5}$ as functions of temperature. The coercivity decreases with increasing temperature for both materials. For $\mathrm{SmCo}_{5}$, the coercivity decreases from $11 \mathrm{kOe}$ at room temperature to $0.15 \mathrm{kOe}$ at $500{ }^{\circ} \mathrm{C}$, whereas the respective values for $\mathrm{YCo}_{5}$ are $3.6 \mathrm{kOe}$ and $0.6 \mathrm{kOe}$. In contrast, the shape of the hysteresis loops (not shown here) did not exhibit any significant temperature or materials dependence.

\section{DISCUSSION}

To explain the temperature behavior of the coercivity, we first analyze the temperature dependence of the anisotropy, which governs the temperature dependence of the coercivity, and then briefly discuss some micromagnetic aspects of the problem. 


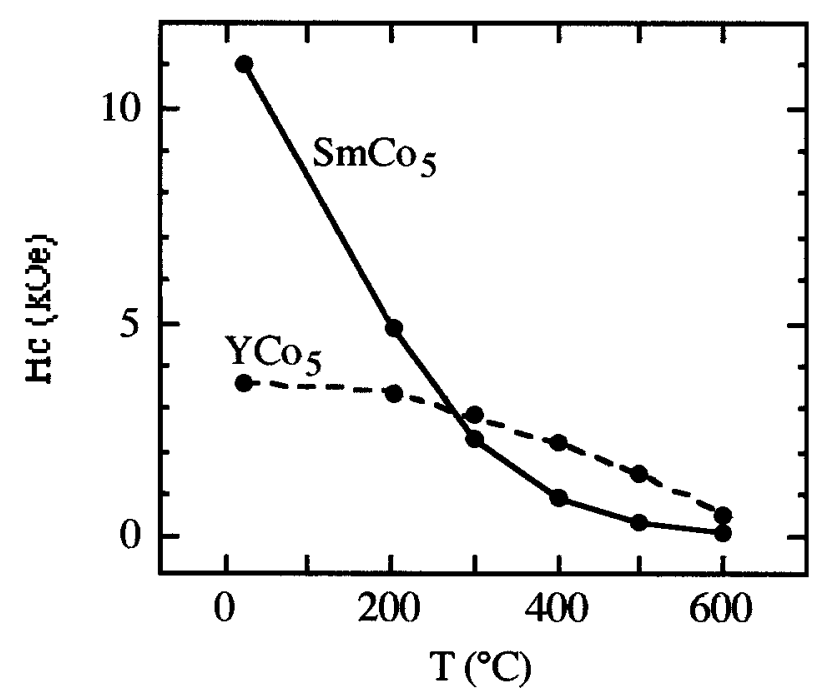

Fig. 1. Experimental coercivity as a function of temperature.

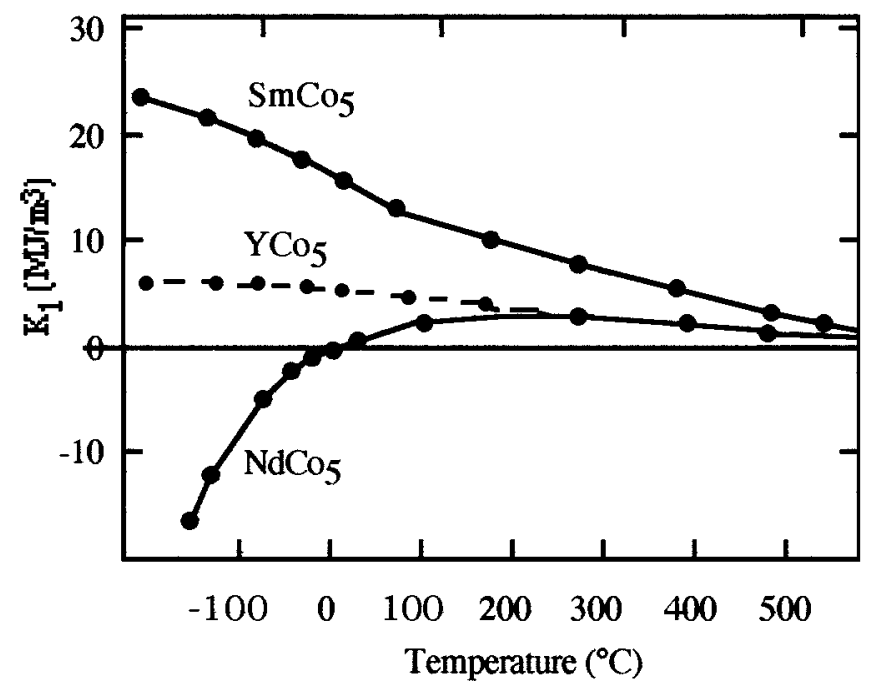

Fig. 2. Temperature dependence of the anisotropy of some $\mathrm{RCO}_{5}$ intermetallics.

\section{A. Temperature Dependence of the Anisotropy}

As a rough approximation, the "intrinsic" coercivity $H_{c}=$ ${ }_{i} H_{c}$ of permanent magnets scales as

$$
H_{c}=2 \alpha K_{1} / \mu_{o} M_{s}
$$

where

$K_{1}$ is the first-order anisotropy constant,

$M_{s} \quad$ is the spontaneous magnetization, and

$\alpha$ is a real-structure-dependent dimensionless factor.

Usually, $\alpha \approx 0.3$ for optimized permanent magnets [9]. The main contribution to the temperature dependence of the coercivity originates from the temperature dependence of $K_{1}$ [2], [8]. $M_{s}$ is much less temperature dependent [8], whereas $\alpha$ is essentially constant unless there are irreversible structural changes on heating.

Fig. 2 shows the temperature dependence of $K_{1}$ for a $\mathrm{NdCo}_{5}$, $\mathrm{YCo}_{5}$, and $\mathrm{SmCo}_{5}$ [2]. The convergent character of the curves shows that the rare-earth anisotropy is less important at high temperatures: the magnetization of the rare-earth ions must be coupled to the magnet's main transition-metal magnetization, but the rare-earth transition-metal intersublattice exchange is comparatively weak and easily overcome by thermal excitation [2], [6]. The striking anisotropy differences between isostructural rare-earth compounds-compare $\mathrm{NdCo}_{5}$ and $\mathrm{SmCo}_{5}$ in Fig. 2-are well known to reflect the shape of the rare-earth $4 f$ electron clouds (see e.g., [2], [8]). The shape of the $4 f$ shells is given by the Stevens factor $\alpha_{J}$ in the case of uniaxial crystals (hexagonal, tetragonal, and rhombohedral). The elements $\mathrm{Ce}$, Pr, Nd, Tb, Dy, and Ho have oblate (pancake-like) $4 f$ shells $\left(\alpha_{J}<0\right)$, whereas $\mathrm{Sm}, \mathrm{Er}, \mathrm{Tm}$, and $\mathrm{Yb}$ are characterized by prolate (cigar-like) $4 f$ shells $\left(\alpha_{J}>0\right)$. In a given crystalline environment, prolate and oblate ions give opposite anisotropy contributions, which explains the different low-temperature anisotropies of $\mathrm{NdCo}_{5}$ and $\mathrm{SmCo}_{5}$.

Gadolinium, which has a half-filled $4 \mathrm{f}$ shell, and the "nonmagnetic" rare earths Y, La, and Lu exhibit $4 f$ shells with spherical symmetry, so that $\alpha_{J}=0$ and the corresponding anisotropy contribution is zero. The anisotropy of $\mathrm{YCo}_{5}$ therefore originates from the Co sublattice. Figs. 1 and 2 show that the rareearth contribution to anisotropy and coercivity is negligible at high temperatures.

\section{B. Micromagnetic Effects}

The intrinsic temperature dependence of the anisotropy (Fig. 2) provides a qualitatively correct explanation of the coercivity. However, Fig. 1 shows that the high-temperature coercivity of $\mathrm{YCo}_{5}$ is actually somewhat higher than that of $\mathrm{SmCo}_{5}$. This supports our original idea that $\mathrm{Sm}$ may well be replaced by Y, but it doesn't make sense from a purely intrinsic point of view. In terms of Eq. (1), the reason for this effect is well known: small structural changes may give rise to disproportionally large changes in the parameter $\alpha$ [2]. The $\mathrm{YCo}_{5}$ and $\mathrm{SmCo}_{5}$ magnets are structurally very similar (nanostructured random-anisotropy magnets), but there remain small differences in stoichiometry and grain structure that produce easily measurable coercivity deviations.

It is important to keep in mind that the present predictions refer to single-phase materials. Two-phase materials, such as cellular $1: 5 / 2: 17$ magnets, exploit subtle differences between the anisotropies of the phases involved, and the coercivity may actually reach a maximum at high temperatures [2]-[5].

As a first-order approach, the magnets can be considered as isotropic and weakly interacting ensembles of Stoner-Wohlfarth particles. In the hard-magnetic limit [10], the energy product can be approximated by

$$
(B H)_{\max }=\frac{\mu_{o} M_{s}^{2}}{16}\left(1-\frac{\mu_{o} M_{s}^{2}}{K_{1}}+\frac{4 A}{R^{2} K_{1}}\right)
$$

where $A$ is the exchange stiffness and $R$ is an appropriately defined average grain radius. For $K_{1}=8$, the "ideal" isotropic energy product of $\mu_{o} M_{s}^{2} / 16$ is reproduced, whereas the second and third terms in the bracket describe the onset of soft magnetism and the remanence enhancement, respectively. Equation (2) shows that very hard isotropic materials with sufficiently small grain sizes exhibit a remanence-enhanced energy product, 
but it is difficult to predict to what extent this remains true at elevated temperatures, where the magnets become softer.

\section{CONCLUSIONS}

We have shown that the high-temperature performance of the Y-Co magnets is comparable to that of similarly processed isotructural Sm-Co magnets. This may be used to develop rareearth-free high-temperature permanent magnets having moderate energy products.

\section{ACKNOWLEDGMENT}

I. A. Al-Omari would like to thank Dr. L. Yue for helpful assistance and discussion.

\section{REFERENCES}

[1] K. Kumar, "RETM 5 and $\mathrm{RE}_{2} \mathrm{TM}_{17}$ permanent magnets development," J. Appl. Phys., vol. 63, pp. R13-R57, 1988.
[2] R. Skomski and J. M. D. Coey, Permanent Magnetism. Bristol: Institute of Physics, 1999.

[3] J. F. Liu, T. Chui, D. Dimitrov, and G. C. Hadjipanayis, "Abnormal temperature dependence of intrinsic coercivity in $\mathrm{Sm}(\mathrm{Co}, \mathrm{Fe}, \mathrm{Cu}, \mathrm{Zr})_{z}$ powder materials," Appl. Phys. Lett., vol. 73, pp. 3007-3009, 1998.

[4] J. Zhou, R. Skomski, C. Chen, G. C. Hadjipanayis, and D. J. Sellmyer, "Sm-Co-Cu-Ti high-temperature permanent magnets," J. Appl. Phys., vol. 77, pp. 1514-1516, 2000.

[5] D. Goll, I. Kleinschroth, W. Sigle, and H. Kronmüller, "Melt-spun precipitation-hardened $\mathrm{Sm}_{2}(\mathrm{Co}, \mathrm{Cu}, \mathrm{Fe}, \mathrm{Zr})_{17}$ magnets with abnormal temperature dependence of coercivity," Appl. Phys. Lett., vol. 76, pp. 1054-1056, 2000.

[6] R. Skomski, "Finite-temperature behavior of anisotropic two-sublattice magnets," J. Appl. Phys., vol. 83, pp. 6724-6726, 1998.

[7] D. Leslie-Pelecky and R. L. Schalek, "Effect of disorder on the magnetic properties of Smo, ," Phys. Rev. B, vol. 59, pp. 457-462, 1999.

[8] J. M. D. Coey, "Intermetallic compounds and crystal-field interactions," in Science and Technology of Nanostructured Magnetic Materials, G. C. Hadjipanayis and G. A. Prinz, Eds. New York: Plenum Press, 1991, pp. 439-458.

[9] H. Kronmüller, "Theory of nucleation fields in inhomogeneous ferromagnets," Phys. Stat. Sol. (b), vol. 144, pp. 385-396, 1987.

[10] R. Skomski, J.-P. Liu, and D. J. Sellmyer, "Permanent magnetism in exchange-coupled nanocomposites," in Mat. Res. Soc. Symp. Proc., vol. 562, 1999, pp. 309-320. 